\title{
Contingent negative variation in adults with Gilles de la Tourette syndrome
}

\author{
T C A M VAN WOERKOM,${ }^{*} \dagger$ C FORTGENS, $\ddagger$ B J M VAN DE WETERING,$\S$ \\ C M C MARTENS*
}

From the Departments of Neuropsychiatry* and Medical Physics, $\ddagger$ Psychiatric Centre Rosenburg, The Hague; the Department of Clinical Neurology, the Municipal Hospitals, $\uparrow$ The Hague; the Department of Psychiatry, University Hospital "Dijkzigt",§ Rotterdam, The Netherlands

SUMmaRY Three deflections or waves of the Contingent Negative Variation (CNV): the Slow Negative Wave (SNW), the Terminal CNV (TCNV) and the Post Imperative Negative Variation (PINV) were studied in 18 adults with Gilles de la Tourette syndrome and in 15 controls. The patients showed a reduced SNW, a normal TCNV and an increased PINV. Moreover, at the right parietal region the patients demonstrated a decreased SNW, TCNV and PINV. The results are discussed in relation to behavioral and neuropsychological disturbances found in Gilles de la Tourette syndrome.

The Gilles de la Tourette syndrome is a neuropsychiatric disorder, which consists of lifelong, fluctuating, multiple motor, vocal and sensory tics. ${ }^{12}$ Many patients also have obsessions, compulsions and attentional difficulties. ${ }^{1-8}$ Generalised anxiety and depression are also often observed. ${ }^{1378}$ As shown by the high degree of distraction and echo phenomena Gilles de la Tourette patients seem to be highly sensitive to stimuli around them. ${ }^{178}$ Echo phenomena appear to be related to obsessive compulsive signs. ${ }^{7}$ Hitherto no pathologic anatomic correlate of Gilles de la Tourette syndrome has been found. Nonspecific electroencephalographic abnormalities occur in a minority of the patients ${ }^{910}$ but short latency potentials appear to be normal. ${ }^{9}$

The Contingent Negative Variation (CNV) is a long latency event-related potential. It is usually obtained in a S1-S2 paradigm. S1 is a warning stimulus which is followed after a fixed interval by $S 2$, the imperative stimulus requiring a task, for example, a specific motor response (fig 1). ${ }^{11-13}$ By presenting a series of these S1-S2 stimuli, and averaging the electroencephalographic responses, the CNV response can be obtained. The CNV consists of a series of deflections or waves. Three major deflections

Address for reprint requests: $\operatorname{Dr}$ T C A M van Woerkom, Department of Clinical Neurology, The Municipal Hospitals, Leyweg 275, $2545 \mathrm{CH}$ The Hague, The Netherlands.

Received 28 July 1987 and in revised form 8 December 1987. Accepted 15 December 1987 of the CNV are considered in this study: the Slow Negative Wave (SNW), the Terminal CNV (TCNV) and the Post Imperative Negative Variation (PINV). The SNW, often referred to as early CNV or O-wave, is elicited by $\mathrm{S} 1$ and depends upon its physical characteristics, but also upon the task relevance of $S 1 .^{11}{ }^{12}$ The SNW is sensitive to attentional and distractional factors, enhancing respectively decreasing its amplitude. $^{11-15}$ The TCNV or Late CNV precedes $\mathrm{S} 2$ and is related to the task attached to $\mathrm{S} 2 .{ }^{11}{ }^{12}$ The TCNV shares many characteristics with the Bereitschaftpotential or readiness potential. ${ }^{12}$ After S2, the CNV deflection usually returns to the baseline. The PINV is a prolonged negativity after S2. The PINV has been found in several categories of psychiatric patients, ${ }^{111316}$ but can be elicited in normal subjects as well after an unexpected temporary change in the S1-S2 paradigm. ${ }^{11}$

Since attentional disturbances and increased distraction often occur in Gilles de la Tourette patients, ${ }^{128}$ we sought to determine whether the $\mathrm{CNV}$, in particular the SNW, is altered in the syndrome.

\section{Methods}

Patients and controls All 18 patients (mean age $23 \mathrm{yr}$, standard deviation 7) fulfilled the diagnostic criteria for Gilles de la Tourette syndrome according to DSM-III (American Psychiatric Association 1980). Sixteen patients were righthanded. Two patients were treated with low doses of pimozide. The control group consisted of 15 members (all 630 


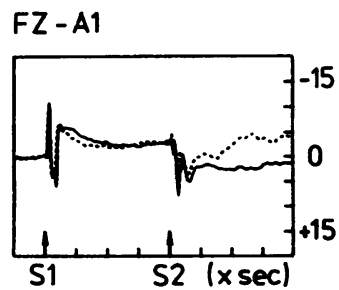

CZ-A1

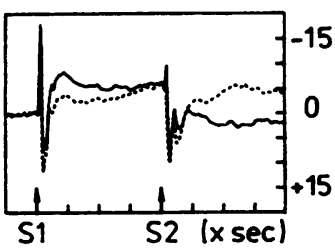

PZ-A1

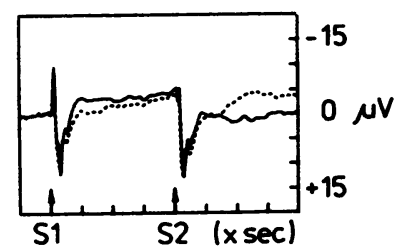

C3-A1

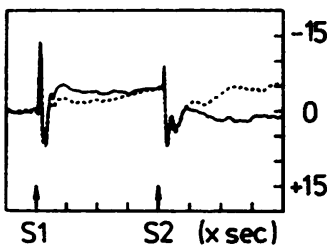

$\mathrm{C} L-\mathrm{A} 2$

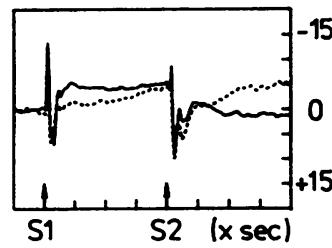

P3-A1

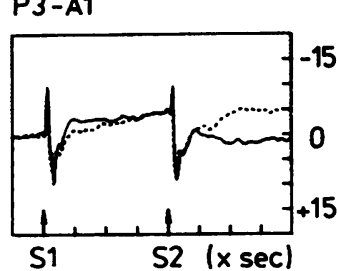

P4-A2

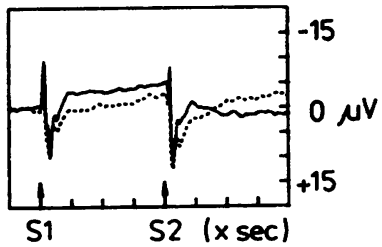

Fig 1 Grand averages of the CNV's in the controls (-) and the patients (--) S1 is the warning stimulus followed at 4 s by the imperative stimulus S2. Note the asymmetry between P3 and P4 in the Gilles de la Tourette patients.

righthanded) of the hospital staff (mean age $29 \mathrm{yr}$, standard deviation 5).

Recording and test procedures The subjects were seated in a light-dimmed room. They were told to stay relaxed and to direct their gaze to a dark spot $(70 \mathrm{~mm}$ diameter) on a white translucent screen $2 \mathrm{~m}$ in front of them. The subjects and the screen were surrounded by featureless curtains to minimise distraction. The conventional S1-S2 paradigm was used. S1 was a tone burst $(250 \mathrm{~Hz}, 50 \mathrm{~ms}, 50 \mathrm{~dB}$ SPL), S2 was a series of light flashes $(40 \mathrm{~Hz})$ projected on the back of the translucent screen. The subjects were instructed to stop S2 as quickly as possible by pressing a microswitch with their preferred hand. No instructions were given to control eye blinks, eye movements or tics. Eye movements and blink artifacts were subtracted using four EOG derivations, eliminating the need to disregard contaminated trials. ${ }^{17}$ So the subjects could blink or tic freely to avoid increased inattentions, especially in the patients. Thirty trials were delivered, the interstimulus interval was $4 s$ and the interval between successive S1s varied at random between 13 and 19s.

The following EEG derivations (10/20 system) were used: Fz-A1, Cz-A1, Pz-A1, C3-A1, C4-A2, P3-A1 and P4-A2 (filter settings: $0.016-35 \mathrm{~Hz}, 3 \mathrm{~dB}$ ). The channels were sampled simultaneously $(100 \mathrm{~Hz})$ starting $1 \mathrm{~s}$ before S1 until $4 \mathrm{~s}$ after S2.

The following $\mathrm{CNV}$ components were determined: the Slow Negative Wave (SNW), defined as the average amplitude between 600 and $1000 \mathrm{~ms}$ after S1; the Terminal CNV (TCNV), defined as the average amplitude between 3500 and $4000 \mathrm{~ms}$ after S1; the Post Imperative Negative Variation (PINV), defined as the average amplitude of the eventrelated response between 2000 and $3000 \mathrm{~ms}$ after S2 (fig 1). The average EEG of $1 \mathrm{~s}$ before the onset of S1 was used as a reference for the amplitude measurements. Differences between groups were tested with the 3-factor ANOVA with repeated measures. The Tukey-test was used for multiple comparisons between means.

\section{Results}

The 3-factor ANOVA with repeated measures on subjects revealed a significant group $X$ wave interaction $(F(2,62)=11.4 ; p<0.01)$. In other words, the waves in the controls were different from the waves in the patients. Also, there was a significant group $X$ derivation $X$ wave interaction $(F(12,372)=2 \cdot 13$;

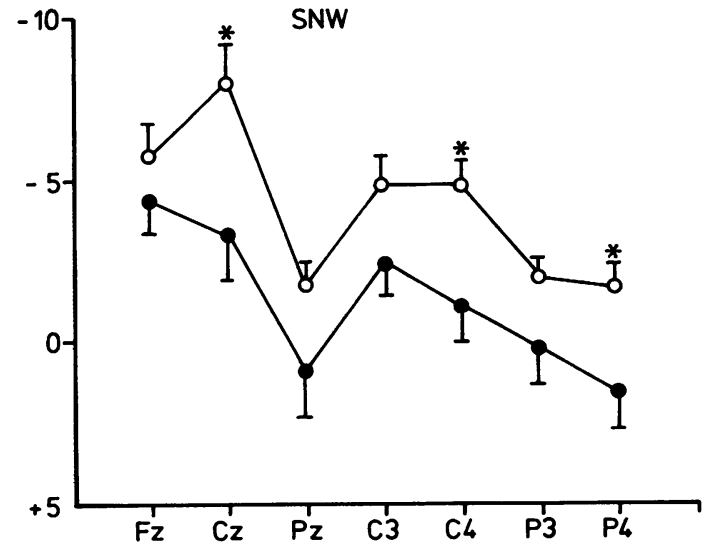

Fig 2 The average SNW of the controls (open circles) and patients (closed circles) expressed in $\mu V$. The vertical bars indicate standard error of the mean. The symbols are interconnected to aid visual inspection. Significant differences between controls and patients are indicated with asterisks. Note the difference in distributions between the controls and the patients (SNW being larger at Fz than at $\mathrm{Cz}$ in the patients, and smaller in the controls). 
$\mathrm{p}<0.05)$. So, the different waves had different distributions over the skull for both the controls and the patients. In figs 2-4 the interaction between groups and waves and derivations can be seen, the groups $X$ waves interaction being most pronounced. The SNW of the patients starts less negatively than the SNW of the controls (fig 2). The PINV of the patients, at the end of the response, is more negative than the PINV of the controls (fig 4).

For the SNW in the patients and controls there was a significant interaction between groups and derivations $(F(6,186)=2.35 ; p<0.05)$. At all derivations the patients had a decreased SNW. This decrease was significant at $\mathrm{Cz}(\mathrm{p}<0.01), \mathrm{C} 4(\mathrm{p}<$ $0.05)$ and P4 (p < 0.05) (fig 2). Furthermore, there was a difference between the SNWs measured at Fz and at $\mathrm{Cz}(\mathrm{p}<0.01)$. In the controls the SNW was larger at $\mathrm{Cz}$ than at $\mathrm{Fz}$, whereas in the patients the SNW was larger at $\mathrm{Fz}$ than at $\mathrm{Cz}$.

With respect to the TCNV no significant interaction was found between groups and derivations. Both groups had their maximum TCNV over the vertex (fig 3). For each derivation, the patients' TCNV and PINV were about equal in size. Their PINV was significantly more negative than that of the controls $(\mathrm{F}(1,31)=11.7 ; \mathrm{p}<0.01)$. The a posteriori Tukeytest revealed that this effect was significant at all derivations but P4: Fzp $<0.01 ; \mathrm{Cz} p<0.01 ; \mathrm{Pzp}<0.05$; C3 p < 0.01; and P3 p < 0.01 (fig 4). At Cz a PINV larger than $-2 \mu \mathrm{V}$ was found in $72 \%(13 / 18)$ of the patients, but only in $20 \%(3 / 15)$ of the controls.

Examining the left-right differences ( $\mathrm{C} 3-\mathrm{C} 4$ and P3-P4), the patients were consistently more negative at P4 than at P3 for the SNW (p $<0.05)$, TCNW $(p<0.05)$ and the PINV $(p<0.01)$. This effect was not encountered in the controls.

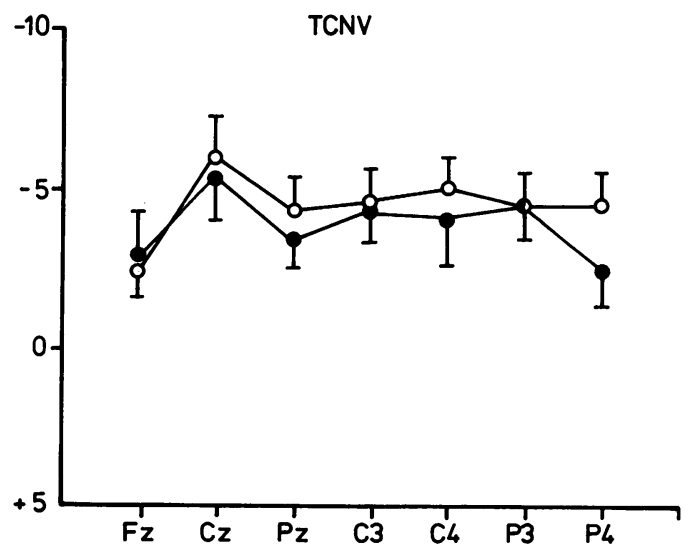

Fig 3 The average TCNV of the controls (open circles) and patients (closed circles).

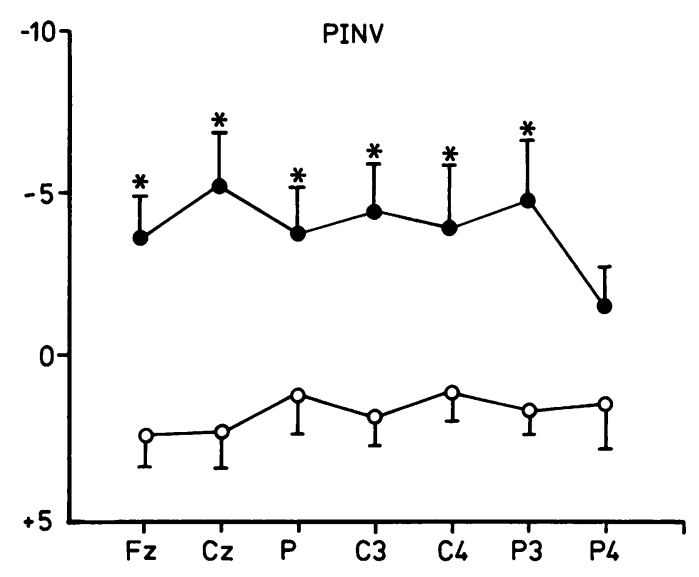

Fig 4 The average PINV of the controls (open circles) and patients (closed circles).

Finally, the reaction times of the controls and the $\frac{\partial}{0}$ patients were similar $(241 \mathrm{~ms}$, SD $30 \mathrm{~ms}$, respectively $\vec{G}$ $234 \mathrm{~ms}$, SD $34 \mathrm{~ms}$ ).

\section{Discussion}

The CNV of the Gilles de la Tourette patients differed from the controls in 2 aspects. Firstly, having a lowe negative level at the beginning (SNW), the CNV of the patients ends with an increased PINV reaching a valie similar to the preceding TCNV. Secondly, SNW, TCNV and PINV in the Gilles de la Tourette patients, but not in the controls, demonstrate a remarkable asymmetry characterised by a decreased right parietal (P4) negativity.

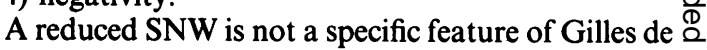
la Tourette syndrome. It has been reported in several $\overrightarrow{\overrightarrow{0}}$ psychiatric diseases and has been related to atten- 3 tional difficulties connected with increased distraction. ${ }^{111316}$ Distraction, irrespective of its nature (external stimuli, too low or too intense arousal, bodily discomfort) appears to be associated with decreased SNW amplitudes. ${ }^{11-15}$ Knott and Irwin $:$ have suggested that in highly emotional subjects 3 . stress, apart from distraction, adds to a smaller $\delta$ SNW. ${ }^{18}$ Gilles de la Tourette patients are easily susceptible to stress. ${ }^{1378}$ Many of them also suffer from 음 distraction resulting in learning disabilities. ${ }^{124}$ In the present study we did not assess psychometricly the level of attention disturbances. However, learning difficulties due to severe distraction were encountered $\sigma$ in eight of the patients.

Owing to their specific obsessive-compulsive nature and as demonstrated by echo phenomena and increased distraction Gilles de la Tourette patients are easily captured by external stimuli, forcing them to 
react immediately. Therefore in our opinion the patients' lowered SNW in response to $\mathrm{Sl}$ may indicate the presence of a higher basic level of background activity, making it less necessary to develop the same amount of transient negativity in response to $S 1$ as the controls. Following the reduced SNW the patients develop a normal TCNV (except at P4).

Prolongation of the CNV deflection after S2 (PINV) also has been observed in psychiatric patients. ${ }^{111316}$ In normal subjects the PINV can develop in stressful conditions ${ }^{19}$ or in case of sustained information processing as a result of uncertainty about the adequacy of the motor response in relation to the significance of S2. ${ }^{11}$ With regard to their reaction times, the patients performed the motor responses perfectly well, at least suggesting adequate motor control over S2. However, possibly because of their obsessive-compulsive character (10 of the patients demonstrated overt obsessions and/or compulsions) associated with pathological doubt, ${ }^{8}$ Gilles de la Tourette patients may feel uncertain of the quality of their response. In contrast to the controls Gilles de la Tourette patients remain, at least for a while, stimulus bound. It is this uncertainty that may be reflected by the PINV.

An intriguing finding within the group of Gilles de la Tourette patients is the consistently decreased negativity of SNW, TCNV and PINV at the right parietal region (P4). Whether this electrophysiological asymmetry is restricted to the parietal region is unknown because in this study frontolateral and temporal derivations were not used. The parietal asymmetry has only been observed in the patients, making it unlikely to be caused by instrumental or methodological artifacts or by handedness. It appears from physiological studies that slow negative waves in response to meaningful stimuli are associated with an increase in cortical activity reflecting neuronal excitation necessary for problem solving. ${ }^{11}$ Therefore it is possible that the asymmetry between $\mathrm{P} 3$ and $\mathrm{P} 4$ indicates a (relatively, PINV) underactivated right parietal cortex. If so, our neurophysiological finding may be consistent with neuropsychological studies which have revealed in Gilles de la Tourette syndrome a decrease in visuoperceptual, visuospatial and visuomotor abilities pointing to a dysfunction of the right parietal region. ${ }^{20-22}$

Possibly, the asymmetric dysfunction is not restricted to the parietal region, other parts of the right hemisphere may be involved as well. ${ }^{21}$ How from a clinical point of view Gilles de la Tourette syndrome could be understood in terms of a right hemisphere dysfunction will have to be investigated more deeply. The right hemisphere plays a dominant role in attention processes and the ability to express affect through emotional prosody in speech (vocal tics?) and by means of facial expression and gestures (motor tics?). ${ }^{23}$

\section{References}

1 Cohen DJ, Detlor J, Shaywitz BA, Leckman JF. Interaction of biological and psychological factors in the natural history of Tourette syndrome: a paradigm for childhood neuropsychiatric disorders. In: Friedhoff AJ, Chase TN, eds. Gilles de la Tourette Syndrome, Advances in Neurology vol 35. New York: Raven Press 1982:31-40.

2 Shapiro ES, Shapiro AK. Semiology, nosology and criteria for tic disorders. Rev Neurol (Paris) 1986;142:824-32.

3 Corbett JA, Mathews AM, Connell PH, Shapiro DA. Tics and Gilles de la Tourette's syndrome: a follow-up study and critical review. Br J Psychiatry 1969;115:1229-41.

4 Nee LE, Caine ED, Polinsky RJ, Eldridge R, Ebert MH. Gilles de la Tourette syndrome: Clinical and family study of 50 cases. Ann Neurol 1980;7:41-9.

5 Lees AJ, Robertson M, Trimble MR, Murray NMF. A clinical study of Gilles de la Tourette syndrome in the United Kingdom. J Neurol Neurosurg Psychiatry 1984;47:1-8.

6 Frankel M, Cummings JL, Robertson MM, Trimble MR, Ann Hill M, Benson DF. Obsessions and compulsions in Gilles de la Tourette's syndrome. Neurology 1986;36:378-82.

7 Trimble MR, Robertson MM. The psychopathology of tics. In: Marsden CD, Fahn S, eds. Movement Disorders 2. London: Butterworths, 1987:406-22.

8 Pitman RK, Green RC, Jenike MA, Mesulam M-M. Clinical comparison of Tourette's disorder and obsessive-compulsive disorder. Am J Psychiatry 1987;144:1166-71.

9 Krumholz A, Singer HS, Niedermeyer E, Burnite R, Harris K. Electrophysiological studies in Tourette's syndrome. Ann Neurol 1983;14:638-41.

10 Verma NP, Syrigou-Papavasiliou A, LeWitt P. Electroencephalographic findings in unmedicated neurologically and intellectually intact Tourette syndrome patients. Electroencephalogr Clin Neurophysiol 1986;64:12-20.

11 Rockstroh B, Elbert T, Birbaumer N, Lutzenberger W. Slow Brain Potentials and Behavior. Baltimore: Urban and Schwarzenberg 1982.

12 Rohrbaugh JW, Gaillard AWK. Sensory and motor aspects of the contingent negative variation. In: Gaillard AWK, Ritter W, eds. Tutorials in ERP research: Endogenous Components. Amsterdam: North-Holland 1983:269-310.

13 Tecce JJ, Cattanach L. Contingent negative variation. In: Niedermeyer E, Lopes da Silva F, eds. Electroencephalography, Basic Principles, Clinical Applications and Related Fields. Baltimore: Urban and Schwarzenberg 1982:543-62.

14 Rockstroh B, Elbert T, Lutzenberger W, Birbaumer N. The CNV distraction effect in long anticipation intervals. In: McCallum WC, Zappoli R, Denoth F, eds. Cerebral Psychophysiology, Studies in Event-Related Potentials. Electroencephalogr Clin Neurophysiol suppl 38. Amsterdam: Elsevier 1986:265-6.

15 McCallum WC, Walter WG. The effects of attention and distraction on the contingent negative variation in normal and neurotic subjects. Electroencephalogr Clin Neurophysiol 1968;25:319-29.

16 Timsit-Berthier M. Contingent negative variation (CNV) in psychiatry. In: McCallum WC, Zappoli R, Denoth F, eds. Cerebral Psychophysiology, Studies in Event-Related Potentials. Electroencephalogr Clin Neurophysiol suppl 38. Amsterdam: Elsevier 1986:429-34.

17 Fortgens C, De Bruin MP. Removal of eye movement and ECG artifacts from the non-cephalic reference EEG. Electroencephalogr Clin Neurophysiol 1983;56:90-6.

18 Knott JR, Irwin DA. Anxiety, stress and the contingent negative variation. Arch Gen Psychiatry 1973;29:538-41.

19 Gauthier P, Gottesmann $\mathrm{Cl}$. Etude de la variation contingent 
négative et de l'onde post-impérative en présence d'interférences. Electroencephalogr Clin Neurophysiol 1976;40: 143-52.

20 Incagnoli $T$, Kane $R$. Neuropsychological functioning in Tourette syndrome. In: Friedhoff AJ, Chase TN, eds. Gilles de la Tourette Syndrome, Advances in Neurology vol 35. New York: Raven Press 1982:305-9.

21 Sutherland RJ, Kolb B, Schoel WM, Whishaw IQ, Davies D. Neuropsychological assessment of children and adults with
Tourette syndrome: A comparison with learning disabilities and schizophrenia. In: Friedhoff AJ, Chase TN, eds. Gilles de la Tourette Syndrome, Advances in Neurology vol 35. New York: Raven Press 1982:311-22.

22 Bornstein RA, King G, Carroll A. Neuropsychological abnormalities in Gilles de la Tourette's syndrome. $J$ Nerv Ment $D$ 1983;171:497-502.

23 Mesulam M-M: Principles of Behavioral Neurology. Philadelphia: FA Davis Company 1985.
Brown-Séquard's description of spontaneous cerebellar haemorrhage

A founder-physician of the National Hospital, Queen Square, pioneer investigator of hemisection of the cord, Brown-Séquard should also be remembered for showing that the adrenal glands secreted a vital substance which we now know as cortisol.

Born in 1817 , his father was a Philadelphian sea captain, Charles Edward Brown, who travelled to Mauritius and married Henriette Charlotte Perrine Sequard. He came to Paris with his mother and read Medicine, studying under circumstances of extreme poverty. Always a traveller, he taught midwiffery in New York and Jurisprudence in Virginia. Through the commendation of Sir James Paget he was appointed at Queen Square in 1859, was awarded the FRCS and the FRS in 1860. Darwin sought his acclaim for his Origin of Species; he corresponded with Charcot, Huxley and Pasteur. Leaving London in 1863 he continued to hold posts at Harvard, New York, Geneva and finally settled in Paris taking his friend Claude Bernard's chair. He became a French citizen. He died of a stroke in 1894 and is buried at Montparnasse.

He provided a classic description of primary cerebellar haemorrhage, ${ }^{1}$ delivered at the Royal College of Physicians in February 1861. Brown-Séquard was then physician to the National where the same topic was covered in a combined lecture published in the Lancet "Lecture 111-part 1. Diagnosis of Haemorrhage in the Cerebellum."2 He did not claim priority of description, referring to the papers of Hillairet in $1858^{3}$ and somewhat scathingly to the work of M. Serres (vide infra). He described: "1. Premonitory Symptoms: Headache, giddiness, vertigo with involuntary movements of the head on one side, numbness, formication ... drowsiness, have been noted. 2. Coma: 1 st. The intellectual faculties may remain entire, although very grave symptoms of paralysis appear. 2nd. ... The patient being in a state of torpor and speaking incoherently, ... still able to understand. 3rd. a deep coma exists out of which it is hardly possible to rouse the patient, except for a few moments and then his only sign of intellectual life consists of opening his eyes for a short time. 3. Paralysis: 1st. In many cases ... no local paralysis has been observed. The patients were weak on their limbs, or unable to stand up; 2nd. Hemiplegia is not of so frequent occurrence as it is in cases of cerebral haemorrhage, ... this paralysis has existed in the side opposite to that of the haemorrhage. 3rd. ... to distinguish the cerebellar haemorrhage from the cerebral, is the absence of facial paralysis in the first case and its almost constant existence in the second ... a paralysis of one side of the face can occur in cases of haemorrhage limited to one-half of the cerebellum, and produces considerable pressure on the pons Varolii ... the facial paralysis would be on the side injured in the pons, while the paralysis of the limbs would be on the opposite side. 4th. ... general deficiency of power in muscles of the face ... loss of expression. 5th. ... no deviation of the tongue. 6th. Loss of speech is a less frequent symptom than in cerebral haemorrhage. 7th. A paralysis of the muscles of the globe of the eye and of masticatory muscles has not been noted. 8th. The pupils are sometimes contracted, sometimes dilated and rarely normal, ... therefore differ notably from the majority of cases of cerebral haemorrhage. 4. Anaesthesia and Hyperaesthesia: Anaesthesia is rare. ... In several cases hyperaesthesia has been observed. 5. Alteration of Senses: ... no difference therefore as regards the four head senses except that they are less frequently altered in cerebellar haemorrhage than in the cerebral. 6. Convulsions, Contracture: General or partial convulsions have been observed in about one fourth of the cases ... not above one tenth in cerebral haemorrhage. Convulsions are sometimes followed by contracture, or a tetanic rigidity. 7. Erection of the penis: Serres has published several cases ... not been noted by other writers ... this erection may be caused by an irritation of the pons or medulla. 8 . Vomiting: This is a striking symp⿳亠. tom of haemorrhage in the cerebellum. 9. Pulse: N\& $\infty$ difference between the cerebellar and cerebral haemorrhage ... rather a slow than a rapid pulse. 10. Breathing: More common to find difficulty in breathing in cerebellar haemorrhage than cerebral haemorrhage. Death is more frequent precisely on account of the greater difficulty in breathing."

Brown-Séquard's account tallies closely with more recent series. ${ }^{14}$ though modern descriptions stress the triad of constricted reactive pupils, ${ }^{1}$ periodic respiration ${ }^{2}$ and ipsilateral gaze palsy ${ }^{3}$ with a high incidence of trunkal ataxia and peripheral facial palsy. ${ }^{4}$ It was left to Ballance in 1906 to first treat the condition surgically, though his case was traumatic. ${ }^{5}$

JMS PEARCE

\section{References}

1 Fisher CM, Picard EH, Polak A, Dalal P, Ojemann RG. Acute hypertensive cerebellar haemorrhage: diagnosis and surgical treatment. J Nerv Ment Dis 1965;140:38-57.

2 Brown-Séquard CE. Paralytic, Convulsive and mental affections, Lecture 111.-Part 1. Diagnosis of haemorrhage in the cerebellum. Lancet 1861 ;ii:391-2.

3 Hillairet JB. De l'hemorrhagie cérébelleuse. Archives Generales de Medecine 1858;11:fifth series, 411-32.

4 Ott KH, Kase CS, Ojemann RG, Mohr JP. Cerebellar haemorrhage: diagnosis and treatment. A review of 56 cases. Arch Neurol 1974;31:160-7.

5 Ballance $H$. A case of traumatic haemorrhage into the left lateral lobe of the cerebellum treated by operation with recovery. Surg Gynecol Obstet 1906;3:223-5. 